OPEN ACCESS

Edited by:

Dieter Steinhilber,

Goethe University Frankfurt, Germany

Reviewed by:

G.Enrico Rovati,

University of Milan, Italy

Oliver Werz

Friedrich Schiller University Jena,

Germany

*Correspondence:

Colin D. Funk

funkc@queensu.ca

Specialty section:

This article was submitted to Inflammation Pharmacology,

a section of the journal

Frontiers in Pharmacology

Received: 03 July 2020

Accepted: 24 July 2020

Published: 06 August 2020

Citation:

Funk CD and Ardakani A (2020) A

Novel Strategy to Mitigate the

Hyperinflammatory Response to

COVID-19 by Targeting Leukotrienes.

Front. Pharmacol. 11:1214.

doi: 10.3389/fphar.2020.01214

\section{A Novel Strategy to Mitigate the Hyperinflammatory Response to COVID-19 by Targeting Leukotrienes}

\author{
Colin D. Funk ${ }^{1,2 *}$ and Ali Ardakani ${ }^{2}$ \\ 1 Department of Biomedical and Molecular Sciences, Queen's University, Kingston, ON, Canada, ${ }^{2}$ Scientific Research \\ Division, Novateur Ventures Inc., Vancouver, BC, Canada
}

SARS-CoV-2 causing coronavirus disease 2019 (COVID-19) has wreaked havoc during the global pandemic of 2020 infecting millions and leaving over a half million dead. As a new virus, not previously in the human population, but with similarities to other coronaviruses causing severe acute respiratory distress syndrome (SARS/ARDS), and no known treatments, the race to re-purpose existing drugs and to enlist novel therapeutics is underway. In the half-year since the first cases, we have acquired substantial knowledge of this virus and the clinical course of COVID-19 progression. Results from early clinical trials have revealed two treatments (remdesivir, dexamethasone) that mitigate disease progression but clearly, there is much room for improvement. Initial case reports indicated many succumb to COVID-19 of hypoxic respiratory failure due to ARDS. However, ensuing studies revealed an atypical, immune cell-sequestered, vasculature-inflamed state leading to multiorgan thrombotic complications and end organ failure likely due to hyperinflammatory host responses. This Perspective focuses on a potential mechanism for a key COVID-19 disease progression turning point related to vascular and airway inflammation. The leukotriene lipid mediators have been overlooked with discussion centering on cytokine storms unleashing the deadly form of COVID-19. Leukotrienes possess some of the most potent known activities on immune cell trafficking and vascular leakage. We offer a simple treatment paradigm using two generic drugs targeting the hyperinflammatory response that characterizes the turning point from mild to severe/critical COVID-19 by targeting leukotriene biosynthesis with zileuton (Zyflo ${ }^{\circledR}$ controlled release formulation) and antagonism of the cysteinyl leukotriene 1 receptor with montelukast (Singulair ${ }^{\circledR}$ ).

Keywords: COVID-19, SARS-CoV-2, leukotrienes, cytokine storm, coronavirus, inflammatory response, vascular leak, clinical trial 


\section{INTRODUCTION}

SARS-CoV-2 (Severe acute respiratory syndrome coronavirus 2) is the viral instigator of coronavirus disease 2019 (COVID-19) (Oberfeld et al., 2020; Wu F. et al., 2020; Zhou P. et al., 2020; Zhu et al., 2020). Striking in China in late 2019, the virus has spread to virtually every inhabited space on the globe creating a wave of infection killing over half a million people in the first 6 months of the pandemic ${ }^{1}$. This pneumonia-causing disorder spreads primarily from respiratory droplets of infected individuals in enclosed spaces to mucosal epithelial cells in the upper airway and oral cavity where it gains entry via its homotrimeric spike protein to host-cell expressed angiotensin-converting enzyme-2 (ACE2) receptor binding sites in a protease-dependent manner (Liu et al., 2020; Oberfeld et al., 2020). Viral RNA is released into the cytoplasm and hijacks the cell coordinating a replicationtranscription complex, whereby viral RNAs are translated into a distinct set of proteins. Virion assembly is completed and the viral particles can perpetuate the cycle by infecting new cells in the lower airways (Type II pneumocytes), enterocytes in the gastrointestinal tract, while some eventually enter the bloodstream via damaged host tissues (e.g., alveoli) and will bind to ACE2 in vascular endothelial cells to initiate a cascade of deleterious events throughout the body (Lamers et al., 2020; Oberfeld et al., 2020; Varga et al., 2020).

\section{COVID-19 AS A HYPOXIAVARDS CLINICAL DISORDER WITH A UNIQUE VASCULAR HYPERINFLAMMATORY/ PROCOAGULANT STATE}

COVID-19 can be divided roughly into mild, moderate, severe, and critical cases (Berlin et al., 2020; Chen at al., 2020; Figure 1). The vast majority of infected individuals remain largely asymptomatic or only develop mild symptoms. These four general classifications may be part of a continuum in the same individual or discrete, distinct clinical entities in other cases that do not progress from one category to the next. Once infected with SARS-CoV-2, the median incubation period is 5 days to symptoms, although this can be significantly shorter or longer, presumably due to initial viral load of exposure (Berlin et al., 2020). Initial clinical symptoms include fever, dry and persistent cough, and fatigue with the potential for a wide range of other symptoms (e.g., loss of taste/smell, loss of appetite, dyspnea, headaches, sore throat, myalgia, intestinal discomfort/diarrhea, conjunctivitis) with extensive variations between adults and

\footnotetext{
Abbreviations: COVID-19, Coronavirus disease 2019; SARS-CoV-2, Severe acute respiratory syndrome coronavirus 2; ARDS, acute respiratory distress syndrome; CRP, C-reactive protein; MIS-C, multisystem inflammatory syndrome in children; LT, leukotriene; cysLT, cysteinyl leukotriene; $\mathrm{LTB}_{4}$, leukotriene $\mathrm{B}_{4} ; \mathrm{BLT}_{1}, \mathrm{~B}$ leukotriene receptor subtype 1 ; CysLT $_{1}$, cysteinyl leukotriene receptor subtype 1 ; CysLT $_{2}$, cysteinyl leukotriene receptor subtype 2; CSS, cytokine storm syndrome; GPCR, G protein-coupled receptor; LTRA, leukotriene receptor antagonist; CR, controlled release.

${ }^{1}$ https://coronavirus.jhu.edu/map.html [accessed June 30, 2020]
}

children (Guan et al., 2020; Oberfeld et al., 2020). Severe symptoms leading to hospitalization that progress rapidly to hypoxia and acute respiratory distress syndrome (ARDS) requiring supplemental oxygen and ventilator support are most prevalent in the elderly with underlying co-morbidities such as diabetes, obesity, and cardiovascular disease (Vetter et al., 2020; Du et al., 2020) (see Figure 1). Circulating cytokines, such as IL6 , IL-8, TNF $\alpha$ are significantly elevated in severe COVID-19 patients with documented SARS-CoV-2 infection in pneumocytes and endothelial cells, which leads to severe alveolar damage (Figure 2). In severe cases, lymphocytopenia is evident, with depletion of $\mathrm{CD}^{+}$and $\mathrm{CD} 8^{+}$lymphocyte subsets (Li et al., 2020) in blood. There is associated endothelial cell damage of pulmonary vessels with widespread thrombosis (elevated marker: D-dimer), complement activation and microangiopathy (Ackermann et al., 2020; Becker, 2020; Magro et al., 2020). The patients with severe COVID-19 develop an overwhelming state of inflammation (elevated marker: Creactive protein) with multiorgan dysfunction that has been labeled COVID-19 cytokine storm syndrome (CSS) (England et al., 2020). Comparisons to other disorders including secondary hemophagocytic lymphohistiocytosis (sHLH), macrophageactivation syndrome (MAS), Castleman disease, and the cytokine-release syndrome (CRS) associated with chimeric antigen receptor $\mathrm{T}$ cell therapy (CAR-T)) have been detailed (Becker, 2020; England et al., 2020) but none match precisely what has been seen in COVID-19 CSS. An unusual presentation in children, similar to Kawasaki Disease, termed MIS-C (multisystem inflammatory disease in children) is showing enhanced prevalence (Viner and Whittaker, 2020). Increasingly clear is the unique multifocal nature of COVID-19 pathogenesis. SARS-CoV-2 may instigate destruction to blood vessel endothelial cells leading to coagulopathy and strokes, with ensuing damage to kidneys, perhaps pancreatic islet cells, along with neurological problems (Ackermann et al., 2020; Becker, 2020; Mallapaty, 2020; Sardu et al., 2020; Teuwen et al., 2020). Factors affecting disease severity and protective immunity include genetics, age, co-morbidities, sex, ethnicity, demographics, and likely many more that have not yet been defined (Casanova et al., 2020). Overall, SARS-CoV-2 appears to promulgate a novel clinical presentation never before seen in the human population.

\section{MECHANISTIC PATHWAYS EXPLAINING COVID-19 PROGRESSION THAT INVOLVE LEUKOTRIENES}

While a majority of attention has focused on the COVID-19 CSS provoking an over exuberant host immune response to SARS$\mathrm{CoV}-2$ infection in severe/critical cases, some have used a more broad description of a hyperimmune or hyperinflammatory storm (Alunno et al., 2020; Becker, 2020; England et al., 2020; Jamilloux et al., 2020; Jose and Manuel, 2020; Mehta et al., 2020; Panigrahy et al., 2020). In this classification, other inflammationprovoking molecular entities, in addition to cytokines, would be 


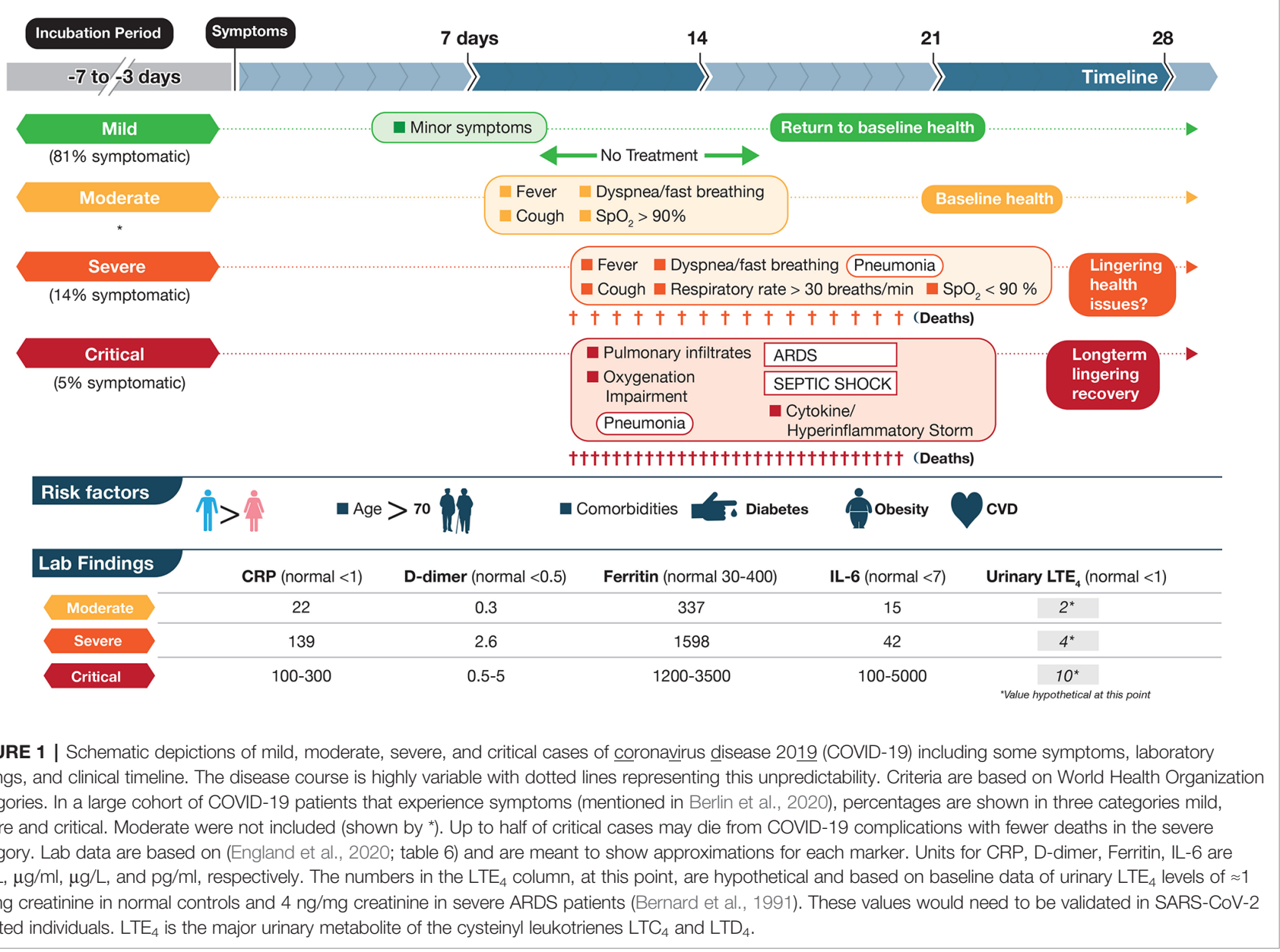

included. Severe disease pathogenesis is likely the result of alveolar pneumocyte injury leading to SARS-CoV-2 dissemination to vascular endothelial cells facilitated by widespread ACE2 expression in vascular beds (Ackermann et al., 2020; Becker, 2020; Teuwen et al., 2020; Varga et al., 2020) (Figure 2). Breaches in vascular integrity have been reported with profound vascular leakage/permeability changes (Ackermann et al., 2020; Becker, 2020; Teuwen et al., 2020). These changes could also influence influx of inflammatory cells throughout the airways and vessel walls. A totally neglected set of molecules not discussed to date include the class of lipid mediators known as leukotrienes (Samuelsson et al., 1987; Funk, 2001; Capra et al., 2007; Peters-Golden and Henderson, 2007) (Figure 2). Leukotrienes are prime candidates to provoke the hyperimmune/inflammatory response in progressing COVID-19, with elevated leukotriene levels detected previously in tracheal aspirates of patients with ARDS (Sala et al., 1991). Leukotriene $\mathrm{B}_{4}\left(\mathrm{LTB}_{4}\right)$ is one of the most potent known chemoattractants for neutrophils (Ford-Hutchinson et al., 1980; Bisgaard et al., 1986) and lymphocyte subsets (Tager et al., 2003; Taube et al., 2006), via signaling through the B leukotriene subtype $1\left(\mathrm{BLT}_{1}\right) \mathrm{G}$ protein-coupled receptor (GPCR) (Sasaki and Yokomizo, 2019). $\mathrm{LTB}_{4}$ is likely one of the key mediators carrying out the huge influx of these cells to airways, which leads to the profound blood lymphocytopenia observed in severe COVID-19 and neutrophilia in airways (Zhang et al., 2020; Li et al., 2020). Moreover, the cysteinyl leukotrienes (cysLTs) $\mathrm{LTC}_{4}$ and $\mathrm{LTD}_{4}$ are among the most profound vascular leakage promoting agents in man and animal models, signaling via two GPCR subtypes CysLT $\mathrm{T}_{1}$ and CysLT $_{2}$ (Samuelsson et al., 1987; Funk, 2001; Maekawa et al., 2002; Lee et al., 2004; Moos et al., 2008; Capra et al., 2015). CysLTs also provoke a number of immune cell actions e.g., macrophage activation, inflammatory cell cytokine secretion and activation of the transcription factor NF- $\mathrm{KB}$, which controls numerous genes involved in inflammation, all of which would heighten the hyperimmune/inflammatory response (Kanaoka and Boyce, 2004; Maeba et al., 2005; Tahan et al., 2008) in COVID-19.

If leukotrienes (LTs) have such potent inflammationpromoting actions, why have they not been considered so far? First, they are not easily measured compared to widely available clinical diagnostic assays of cytokines and other generalized biomarkers of inflammation (e.g., C-reactive protein, CRP) and coagulation (e.g., D-dimer), respectively. There are no routine diagnostic tests in hospitals and other clinical settings for 

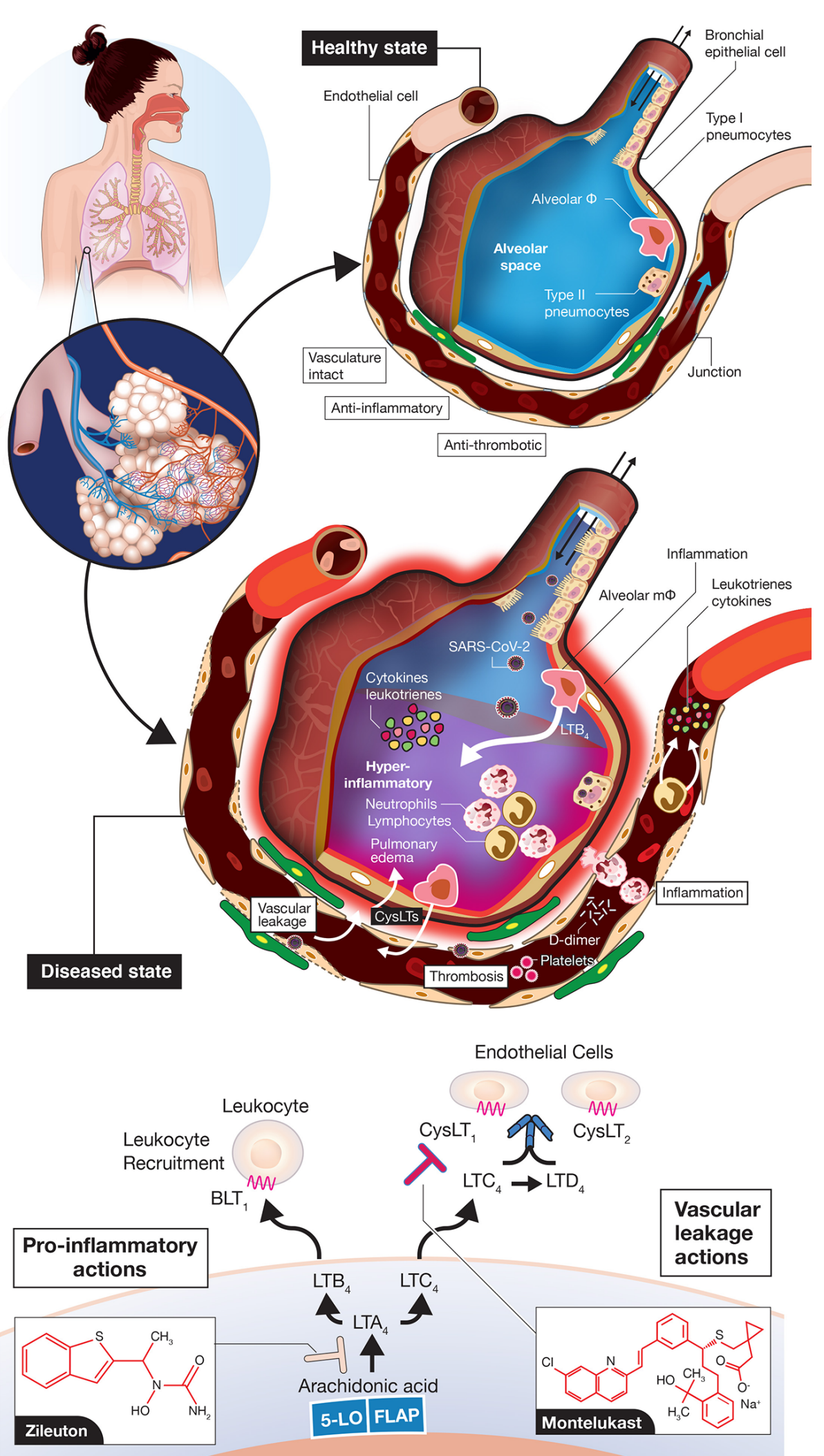

FIGURE 2 | Continued 


\begin{abstract}
FIGURE 2 | Vascular leakage, inflammation-provoking, and thrombotic events in coronavirus disease 2019 (COVID-19). A normal alveolus in the healthy state with associated capillary vessel (top) and SARS-CoV-2 infected alveolus with surrounding vasculature (middle) are shown. Potential roles for LTB 4 to promote inflammatory cell influx into the airways and for CysLTs to initiate vascular leakage are depicted. LTB 4 and CysLTs can be synthesized de novo by alveolar macrophages, infiltrating leukocytes, sentinel mucosal mast cells (not shown here) and via interactions of inflammatory cells with endothelial cells. The figures are "cartoon" representations, so cells/viruses/blood vessels are not to scale. Concepts of the model indicating that COVID-19 is an endothelial disorder are based on (Ackermann et al., 2020; Becker, 2020; Sardu et al., 2020; Teuwen et al., 2020; Varga et al., 2020) but with an emphasis here on leukotriene inflammatory mediators. Depiction of leukotriene biosynthesis along with the two drugs zileuton and montelukast proposed to mitigate disease progression of COVID-19 (bottom). Zileuton, acting intracellularly, inhibits 5-lipoxygenase (5-LO) to decrease leukotriene ligands able to bind downstream receptors BLT 1 (mediating neutrophil/T lymphocyte trafficking) and CysLT receptors (promoting vascular leakage). Montelukast, acting extracellularly, antagonizes selectively $C_{1} \mathrm{C}_{1}$ to dampen inflammation and reduce vascular leakage. FLAP, 5-lipoxygenase-activating protein.
\end{abstract}

measuring LTs. Their measurement most often entails a laborintensive mass spectrometry assay with prior solid-phase extraction from blood or urine (Murphy et al., 2005), with most commercially available ELISA kits not recommended for human diagnostics. Second, lipid inflammatory mediators, in general, receive less attention than their cytokine counterparts due to their labile nature and rapid metabolism. Third, there are very few clinically approved drugs in the leukotriene modifier class (Funk, 2005; Capra et al., 2006; Werz and Steinhilber, 2006). The field to developing successful therapeutics has been fraught with a minefield of abandoned pre-clinical candidates. After $30^{+}$years of targeted research in the field by many leading pharmaceutical companies, there are only a few approved drugs in the pathway ${ }^{2}$; one is the 5-lipoxygenase enzyme inhibitor, which blocks the synthesis of all downstream LTs, known as zileuton (Zyflo ${ }^{\circledR}$ ) (Werz and Steinhilber, 2006; Bouchette and Preuss, 2020) and the other is an antagonist of the $\mathrm{CysLT}_{1}$ receptor, montelukast (Singulair ${ }^{\circledR}$; with two other approved drugs in this class) (Wermuth et al., 2020). No drugs have reached the clinical market for other targets in the leukotriene pathway (Figure 2, bottom) including the 5-lipoxygenase-activating protein (FLAP), leukotriene $\mathrm{A}_{4}$ hydrolase, two subtypes of $\mathrm{B}$ leukotriene receptors $\left(\mathrm{BLT}_{1}, \mathrm{BLT}_{2}\right)$ and for $\mathrm{CysLT}_{2}$, although many pre-clinical candidates have been advanced over the years (Funk, 2005; Werz and Steinhilber, 2006).

\section{DUAL DRUG TREATMENT PARADIGM FOR COVID-19 TARGETING LEUKOTRIENES}

There are currently no approved effective therapies or preventative vaccines to protect the immune naive global population from COVID-19. Over 2500 clinical trials are registered worldwide in attempts to treat the clinical sequelae of SARS-CoV-2 infection ${ }^{3,4}$. Numerous drugs, both approved or in preclinical development, designed to treat other disorders have been repurposed to treat COVID-19 in the first half of 2020. Several drug candidates have already been ruled out as effective agents, based on early trial results (e.g., hydroxychloroquine), with only two (the antiviral remdesivir and the synthetic

\footnotetext{
$\overline{{ }^{2} \text { https://www.aaaai.org/conditions-and-treatments/drug-guide/leukotriene- }}$ modifiers [accessed June 29, 2020]

${ }^{3}$ https://clinicaltrials.gov/ct2/results?cond=COVID-19 [accessed June 29, 2020]

${ }^{4}$ https://public.tableau.com/profile/marinamarin\#!/vizhome/covidTrials/COVID19ClinicalTrialsExplorer [accessed June 29, 2020]
}

glucocorticoid dexamethasone) showing partial efficacy in randomized clinical trials (Goldman et al., 2020; Recovery Collaborative Group, 2020; Wang et al., 2020). Current WHO guidelines (as of June 30, 2020) do not recommend treatment with any drugs outside of clinical trials, although some regional authorities are now incorporating dexamethasone into treatment guidelines to combat the hyperinflammatory stages of severe COVID (Mahase, 2020).

At the time of writing this perspective, we have found only three papers out of $>20,000$ listed on PubMed mentioning COVID, that hypothesize the use of a clinically approved drug targeting leukotrienes, known as leukotriene modifiers (Funk, 2005), namely the leukotriene receptor antagonist (LTRA) montelukast for COVID-19 treatment (Almerie and Kerrigan, 2020; Bozek and Winterstein, 2020; Fidan and Aydoğdu, 2020). In addition, the first and only registered trial mentioning leukotrienes was just recently registered (May 15, 2020) The COvid-19 Symptom MOntelukast Trial (COSMO) ${ }^{5}$. While these are welcome forays into the area, we believe for optimal chances to relieve the hyperimmune/inflammatory storm in COVID-19 it will be necessary to not only block CysLT signaling with montelukast but also the other LT receptors, $\mathrm{CysLT}_{2}$ and $\mathrm{BLT}_{1}$. Since there are no approved blockers for these latter two receptors, it would be imperative to reduce production of all LTs from inflammatory cells before the deadly orchestration of hyperinflammation and cascade of procoagulant actions can take place. This could be achieved potentially with both a 5-lipoxygenase inhibitor (zileuton) and an LTRA (montelukast). Montelukast has been in widespread use for over 20 years to treat the airway inflammatory symptoms of mild-moderate asthma and allergic rhinitis and has an excellent safety profile (Jones et al., 1995; Wermuth et al., 2020). However, zileuton, also used for the same indication and on the market for $>20$ years (Rubin et al., 1991; Bouchette and Preuss, 2020), has been used much less frequently mainly due to weaker potency (large $600 \mathrm{mg}$ tablets) and poor pharmacokinetics (increased dosing) with the potential for hepatotoxicity (Funk, 2005; Werz and Steinhilber, 2006; Bouchette and Preuss, 2020). The newer controlled release (CR) formulation (two tablets, bid) obviates partially the pharmacokinetics issue. We suggest a treatment paradigm with two leukotriene modifiers zileuton $\mathrm{CR} /$ montelukast in individuals presenting with minor symptoms and receiving diagnosis of a positive test for SARS-CoV-2. The drugs would be administered orally for a period of approximately 1-3 weeks

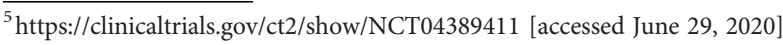


until symptoms resolve completely and diagnosis indicating negative for SARS-CoV-2 infection. This regimen could be added, in theory, as a trial arm to an existing protocol (similar to the Phase III COSMO trial) or as a standalone trial to avoid the potentially fatal hyperinflammatory response.

\section{DISCUSSION}

The rationale for the role of leukotrienes in COVID-19 pathogenesis is clear. A wealth of information exists on elevated LTs in ARDS/sepsis/end organ failure in humans and efficacy of both zileuton and montelukast in various preclinical models (Sprague et al., 1989; Davis et al., 1990; Bernard et al., 1991; Westcott et al., 1991; Collin et al., 2004; Khodir et al., 2014; Monteiro et al., 2014). The roles of LTs in COVID-19 have been neglected to date. To strengthen the case for LT involvement in COVID-19 severity, non-invasive measurements of the major urinary metabolite of cysLTs, known as $\mathrm{LTE}_{4}$ (Sala et al., 1990), should be performed in normal controls and people infected at various stages with SARS-CoV-2 (Figure 1), as previously executed in ARDS patients and controls (Bernard et al., 1991; Sala et al., 1991; Westcott et al., 1991). By targeting vascular permeability, immune modulating and general inflammation-dampening effects at the CysLT $_{1}$ level with montelukast (Dahlén et al., 1981; Maeba et al., 2005; Capra et al., 2007; Tahan et al., 2008; Khodir et al., 2014) and LT biosynthesis with the 5-lipoxygenase inhibitor zileuton, to block both arms of the LT pathway (Figure 2) and remove ligands for another key receptor regulating vascular permeability, CysLT 2 (Moos et al., 2008), as well as inflammatory cell recruitment and endothelial cell adhesion via $\mathrm{BLT}_{1}$ receptor (Ford-Hutchinson et al., 1980; Tager et al., 2003; Taube et al., 2006; Sasaki and Yokomizo, 2019), there is a sound scientific basis for alleviating disease progression from mild to severe-critical stages of COVID-19 (Figures 1 and 2).

Both drugs are generic. While montelukast is inexpensive (about $\$ 1 /$ day), the zileuton CR formulation is rather expensive (about $\$ 100$ day), only available in certain countries (e.g., USA, but not in Canada), and requires a sophisticated process to manufacture the $\mathrm{CR} /$ instant release formulation. This pricing is still much less than a 5 -day course of the antiviral drug remdesivir (over \$3,000 USD) ${ }^{6}$, which has shown limited efficacy to date (Goldman et al., 2020). Drug-drug interactions may have to be monitored (liver function tests). While zileuton is metabolized primarily via CYP1A2 and montelukast via CYP2C8, both are metabolized by the same secondary CYP450 liver enzymes (e.g., 2C9, 3A4) (Funk, 2005). Since the treatment paradigm we are proposing is a single, shortterm treatment, hepatic function monitoring should not be a major concern since hepatotoxicity, when it does occur, usually happens after a month and is infrequent with zileuton alone ${ }^{7}$. The timing of drug administration during the clinical course of COVID-19 is important, especially so, for a general immune system dampening

\footnotetext{
${ }^{6}$ https://endpts.com/gilead-opts-for-3120-us-insurer-price-for-covid-19-drugremdesivir-let-the-debate-begin/ [accessed June 30]

${ }^{7}$ https://www.ncbi.nlm.nih.gov/books/NBK548397/ [accessed June 29, 2020]
}

treatment like dexamethasone, which interestingly may also diminish leukotriene production by virtue of its effects to block substrate supply via the enzyme cytosolic phospholipase $\mathrm{A}_{2}$ (Yao et al., 1999). The initial host antiviral immune response to SARSCoV-2 involves steps of innate immunity implicating interferons (Zhou Q. et al., 2020), so dexamethasone may quell the initial host antiviral response. Leukotrienes, while generally considered "villain" inflammatory mediators, are in some contexts of pathogen invasion deemed innate effectors of the immune response but not for all cases in pre-clinical models (Secor et al., 1998; Peters-Golden et al., 2005; Flamand et al., 2007). The timing for zileuton/montelukast administration in humans with COVID19 should be addressed.

Montelukast has been predicted to bind to the SARS-CoV-2 main protease (MPro) and could perhaps disrupt viral replication (Almerie and Kerrigan, 2020; Wu C. et al., 2020). A coordinated network of lipid signaling molecules including LTs, as well as cytokines, orchestrates proper leukocyte recruitment in settings of inflammation (Sadik and Luster, 2012). In COVID-19, providing the zileuton/montelukast combination prior to out-of-control host inflammatory cell recruitment to the lungs and before pulmonary edema sets in is paramount. Whether females would benefit preferentially from LT modifiers compared to males due to known androgen-dependence of leukotriene biosynthesis (Pergola et al., 2008) and preclinical effects noted with a nonapproved member in this class in other settings (Pace et al., 2017) remains to be determined. We are recommending initiation of treatment with zileuton/montelukast in the $24-48 \mathrm{~h}$ window when a positive test is confirmed and before major symptoms arise, if feasible. The impetus to move forward quickly is vital to combat SARS-CoV-2 while waiting for a preventative vaccine (Funk et al., 2020) or other treatments such as neutralizing antibodies.

\section{DATA AVAILABILITY STATEMENT}

All relevant data is contained within the article. The original contributions presented in the study are included in the article, further inquiries can be directed to the corresponding author.

\section{AUTHOR CONTRIBUTIONS}

$\mathrm{CF}$ and AA conceived the design and concepts. CF wrote the manuscript. Both authors contributed to the article and approved the submitted version.

\section{FUNDING}

This research was funded by Novateur Ventures, Inc.

\section{ACKNOWLEDGMENTS}

We thank Ian Dennis for preparation of figures, Gina Stetsko, and Edward Chong for helpful discussions. 


\section{REFERENCES}

Ackermann, M., Verleden, S. E., Kuehnel, M., Haverich, A., Welte, T., Laenger, F., et al. (2020). Pulmonary Vascular Endothelialitis, Thrombosis, and Angiogenesis in Covid-19. N Engl. J. Med. 383, 120-128. doi: 10.1056/ NEJMoa2015432

Almerie, M. Q., and Kerrigan, D. D. (2020). The association between obesity and poor outcome after COVID-19 indicates a potential therapeutic role for montelukast. Med. Hypotheses. 143:109883. doi: 10.1016/j.mehy.2020.109883

Alunno, A., Carubbi, F., and Rodríguez-Carrio, J. (2020). Storm, typhoon, cyclone or hurricane in patients with COVID-19? Beware of the same storm that has a different origin. RMD Open 6, e001295. doi: 10.1136/rmdopen-2020-001295

Becker, R. C. (2020). COVID-19 update: Covid-19-associated coagulopathy. J. Thromb. Thrombolysis. 50, 54-67. doi: 10.1007/s11239-020-02134-3

Berlin, D. A., Gulick, R. M., and Martinez, F. J. (2020). Severe Covid-19. N Engl. J. Med. doi: 10.1056/NEJMcp2009575

Bernard, G. R., Korley, V., Chee, P., Swindell, B., Ford-Hutchinson, A. W., and Tagari, P. (1991). Persistent generation of peptido leukotrienes in patients with the adult respiratory distress syndrome. Am. Rev. Respir. Dis. 144, 263-267. doi: 10.1164/ajrccm/144.2.263

Bisgaard, H., Helqvist, S., Boudet, L., Venge, P., Dahl, R., and Søndergaard, J. (1986). Chemotactic activity of $\mathrm{LTB}_{4}$ in man. Allergy. 41, 365-372. doi: 10.1111/j.1398-9995.1986.tb00314.x

Bouchette, D., and Preuss, C. V. (2020). “Zileuton," in StatPearls [Internet] (Treasure Island (FL: StatPearls Publishing). 2020 Jan-.

Bozek, A., and Winterstein, J. (2020). Montelukast's ability to fight COVID-19 infection. J. Asthma., 1-2. doi: 10.1080/02770903.2020.1786112

Capra, V., Ambrosio, M., Riccioni, G., and Rovati, G. E. (2006). Cysteinylleukotriene receptor antagonists: present situation and future opportunities. Curr. Med. Chem. 13, 3213-3226. doi: 10.2174/092986706778742963

Capra, V., Thompson, M. D., Sala, A., Cole, D. E., Folco, G., and Rovati, G. E. (2007). Cysteinyl-leukotrienes and their receptors in asthma and other inflammatory diseases: critical update and emerging trends. Med. Res. Rev. 27, 469-527. doi: 10.1002/med.20071

Capra, V., Carnini, C., Accomazzo, M. R., Di Gennaro, A., Fiumicelli, M., Borroni, E., et al. (2015). Autocrine activity of cysteinyl leukotrienes in human vascular endothelial cells: Signaling through the CysLT2 receptor. Prostaglandins Lipid Mediat. 120, 115-125. doi: 10.1016/j.prostaglandins.2015.03.007

Casanova, J. L., Su, H. C., and Human Genetic Effort, COVID (2020). A Global Effort to Define the Human Genetics of Protective Immunity to SARS-CoV-2 Infection. Cell. 181, 1194-1199. doi: 10.1016/j.cell.2020.05.016

Chen, G., Wu, D., Guo, W., Cao, Y., Huang, D., Wang, H., et al. (2020). Clinical and immunological features of severe and moderate coronavirus disease 2019. J. Clin. Invest. 130, 2620-2629. doi: 10.1172/JCI137244

Collin, M., Rossi, A., Cuzzocrea, S., Patel, N. S., Di Paola, R., Hadley, J., et al. (2004). Reduction of the multiple organ injury and dysfunction caused by endotoxemia in 5-lipoxygenase knockout mice and by the 5-lipoxygenase inhibitor zileuton. J. Leukoc. Biol. 76, 961-970. doi: 10.1189/jlb.0604338

Dahlén, S. E., Björk, J., Hedqvist, P., Arfors, K. E., Hammarström, S., Lindgren, J. A., et al. (1981). Leukotrienes promote plasma leakage and leukocyte adhesion in postcapillary venules: in vivo effects with relevance to the acute inflammatory response. Proc. Natl. Acad. Sci. U. S. A. 78, 3887-3891. doi: 10.1073/ pnas.78.6.3887

Davis, J. M., Meyer, J. D., Barie, P. S., Yurt, R. W., Duhaney, R., Dineen, P., et al. (1990). Elevated production of neutrophil leukotriene B4 precedes pulmonary failure in critically ill surgical patients. Surg. Gynecol. Obstet. 170, 495-500.

Du, Y., Tu, L., Zhu, P., Mu, M., Wang, R., Yang, P., et al. (2020). Clinical Features of 85 Fatal Cases of COVID-19 from Wuhan: A retrospective observational study. Am. J. Respir. Crit. Care Med. 201, 1372-1379. doi: 10.1164/ rccm.202003-0543OCOnline ahead of print

England, J. T., Abdulla, A., Biggs, C. M., Lee, A. Y. Y., Hay, K. A., Hoiland, R. L., et al. (2020). Weathering the COVID-19 storm: Lessons from hematologic cytokine syndromes. Blood Rev., 07. doi: 10.1016/j.blre.2020.100707

Fidan, C., and Aydoğdu, A. (2020). As a potential treatment of COVID-19: Montelukast. Med. Hypotheses. 142:109828. doi: 10.1016/j.mehy.2020.109828

Flamand, N., Mancuso, P., Serezani, C. H., and Brock, T. G. (2007). Leukotrienes: mediators that have been typecast as villains. Cell. Mol. Life Sci. 64, 2657-2670. doi: $10.1007 /$ s00018-007-7228-2
Ford-Hutchinson, A. W., Bray, M. A., Doig, M. V., Shipley, M. E., and Smith, M. J. (1980). Leukotriene B, a potent chemokinetic and aggregating substance released from polymorphonuclear leukocytes. Nature 286, 264-265. doi: $10.1038 / 286264 \mathrm{a} 0$

Funk, C. D., Laferrière, C., and Ardakani, A. (2020). A snapshot of the global race for vaccines targeting SARS-CoV-2 and the COVID-19 pandemic. Front. Pharmacol. 11, 937. doi: 10.3389/fphar.2020.00937

Funk, C. D. (2001). Prostaglandins and leukotrienes: advances in eicosanoid biology. Science 294, 1871-1875. doi: 10.1126/science.294.5548.1871

Funk, C. D. (2005). Leukotriene modifiers as potential therapeutics for cardiovascular disease. Nat. Rev. Drug Discovery 4, 664-672. doi: 10.1038/ nrd1796

Goldman, J. D., Lye, D. C. B., Hui, D. S., Marks, K. M., Bruno, R., Montejano, R. et al. (2020). Remdesivir for 5 or 10 Days in Patients with Severe Covid-19. N. Engl. J. Med. doi: 10.1056/NEJMoa2015301

Guan, W. J., Ni, Z. Y., Hu, Y., Liang, W. H., Ou, C. Q., He, J. X., et al. (2020). Clinical characteristics of coronavirus disease in China. N. Engl. J. Med. 382, 1708-1720. doi: 10.1056/NEJMoa2002032

Jamilloux, Y., Henry, T., Belot, A., Viel, S., Fauter, M., El Jammal, T., et al. (2020). Should we stimulate or suppress immune responses in COVID-19? Cytokine and anti-cytokine interventions. Autoimmun. Rev. 19:102567. doi: 10.1016/ j.autrev.2020.102567

Jones, T. R., Labelle, M., Belley, M., Champion, E., Charrette, L., Evans, J., et al. (1995). Pharmacology of montelukast sodium (Singulair), a potent and selective leukotriene D4 receptor antagonist. Can. J. Physiol. Pharmacol. 73, 191-201. doi: 10.1139/y95-028

Jose, R. J., and Manuel, A. (2020). COVID-19 cytokine storm: the interplay between inflammation and coagulation. Lancet Respir. Med. 8 (6), e46-e47. doi: 10.1016/S2213-2600(20)30216-2

Kanaoka, Y., and Boyce, J. A. (2004). Cysteinyl leukotrienes and their receptors: cellular distribution and function in immune and inflammatory responses. J. Immunol. 173, 1503-1510. doi: 10.4049/jimmunol.173.3.1503

Khodir, A. E., Ghoneim, H. A., Rahim, M. A., and Suddek, G. M. (2014). Montelukast reduces sepsis-induced lung and renal injury in rats. Can.J. Physiol. Pharmacol. 92, 839-847. doi: 10.1139/cjpp-2014-0191

Lamers, M. M., Beumer, J., van der Vaart, J., Knoops, K., Puschhof, J., Breugem, T. I., et al. (2020). SARS-CoV-2 productively infects human gut enterocytes. Science 369, 50-54. doi: 10.1126/science.abc1669. Online ahead of print

Lee, K. S., Kim, S. R., Park, H. S., Jin, G. Y., and Lee, Y. C. (2004). Cysteinyl leukotriene receptor antagonist regulates vascular permeability by reducing vascular endothelial growth factor expression. J. Allergy Clin. Immunol. 114, 1093-1099. doi: 10.1016/j.jaci.2004.07.039

Li, S., Jiang, L., Li, X., Lin, F., Wang, Y., Li, B., et al. (2020). Clinical and Pathological Investigation of Patients with Severe COVID-19. JCI Insight. 5, 138070. doi: 10.1172/jci.insight.138070

Liu, Y., Ning, Z., Chen, Y., Guo, M., Liu, Y., Gali, N. K., et al. (2020). Aerodynamic analysis of SARS-CoV-2 in two Wuhan hospitals. Nature. 582, 557-560. doi: 10.1038/s41586-020-2271-3

Maeba, S., Ichiyama, T., Ueno, Y., Makata, H., Matsubara, T., and Furukawa, S. (2005). Effect of montelukast on nuclear factor kappaB activation and proinflammatory molecules. Ann. Allergy Asthma Immunol. 94, 670-674. doi: 10.1016/S1081-1206(10)61326-9

Maekawa, A., Austen, K. F., and Kanaoka, Y. (2002). Targeted gene disruption reveals the role of cysteinyl leukotriene 1 receptor in the enhanced vascular permeability of mice undergoing acute inflammatory responses. J. Biol. Chem. 277, 20820-20824. doi: 10.1074/jbc.M203163200

Magro, C., Mulvey, J. J., Berlin, D., Nuovo, G., Salvatore, S., Harp, J., et al. (2020). Complement associated microvascular injury and thrombosis in the pathogenesis of severe COVID-19 infection: a report of five cases. Transl. Res. 5, S1931-S5244. doi: 10.1016/j.trs1.2020.04.007

Mahase, E. (2020). Covid-19: Demand for dexamethasone surges as RECOVERY trial publishes preprint. BMJ 369, m2512. doi: 10.1136/bmj.m2512

Mallapaty, S. (2020). Mounting clues suggest the coronavirus might trigger diabetes. Nature 583, 16-17. doi: 10.1038/d41586-020-01891-8

Mehta, P., McAuley, D. F., Brown, M., Sanchez, E., Tattersall, R. S., Manson, J. J., et al. (2020). COVID-19: consider cytokine storm syndromes and immunosuppression. Lancet. 395, 1033-1034. doi: 10.1016/S0140-6736(20) 30628-0 
Monteiro, A. P., Soledade, E., Pinheiro, C. S., Dellatorre-Teixeira, L., Oliveira, G. P., Oliveira, M. G., et al. (2014). Pivotal role of the 5-lipoxygenase pathway in lung injury after experimental sepsis. Am. J. Respir. Cell Mol. Biol. 50, 87-95. doi: 10.1165/rcmb.2012-0525OC

Moos, M. P., Mewburn, J. D., Kan, F. W., Ishii, S., Abe, M., Sakimura, K., et al. (2008). Cysteinyl leukotriene 2 receptor-mediated vascular permeability via transendothelial vesicle transport. FASEBJ. 22, 4352-4362. doi: 10.1096/fj.08113274

Murphy, R. C., Barkley, R. M., Zemski Berry, K., Hankin, J., Harrison, K., Krank, J., et al. (2005). Electrospray ionization and tandem mass spectrometry of eicosanoids. Anal. Biochem. 346, 1-42. doi: 10.1016/j.ab.2005.04.042

Oberfeld, B., Achanta, A., Carpenter, K., Chen, P., Gilette, N. M., Langat, P., et al. (2020). SnapShot: COVID-19. Cell. 181, 954. doi: 10.1016/j.cell.2020.04.013

Pace, S., Pergola, C., Dehm, F., Rossi, A., Gerstmeier, J., Troisi, F., et al. (2017). Androgen-mediated sex bias impairs efficiency of leukotriene biosynthesis inhibitors in males. J. Clin. Invest. 127, 3167-3176. doi: 10.1172/JCI92885

Panigrahy, D., Gilligan, M. M., Huang, S., Gartung, A., Cortés-Puch, I., Sime, P. J., et al. (2020). Inflammation resolution: a dual-pronged approach to averting cytokine storms in COVID-19? Cancer Metastasis Rev. 39, 337-340. doi: 10.1007/s10555-020-09889-4

Pergola, C., Dodt, G., Rossi, A., Neunhoeffer, E., Lawrenz, B., Northoff, H., et al. (2008). ERK-mediated regulation of leukotriene biosynthesis by androgens: a molecular basis for gender differences in inflammation and asthma. Proc. Natl. Acad. Sci. U. S. A. 105, 19881-19886. doi: 10.1073/pnas.0809120105

Peters-Golden, M., and Henderson, W. R.Jr (2007). Leukotrienes. N. Engl. J. Med. 357, 1841-1854. doi: 10.1056/NEJMra071371

Peters-Golden, M., Canetti, C., Mancuso, P., and Coffey, M. J. (2005). Leukotrienes: underappreciated mediators of innate immune responses. J. Immunol. 174, 589-594. doi: 10.4049/jimmunol.174.2.589

Recovery Collaborative Group, Horby, P., Lim, W. S., Emberson, J. R., Mafham, M., Bell, J. L., et al (2020). Dexamethasone in hospitalized patients with COVID-19preliminary report. N. Engl. J. Med. doi: 10.1056/NEJMoa2021436

Rubin, P., Dubé, L., Braeckman, R., Swanson, L., Hansen, R., Albert, D., et al. (1991). Pharmacokinetics, safety, and ability to diminish leukotriene synthesis by zileuton, an inhibitor of 5-lipoxygenase. Agents Actions Suppl. 35, 103-116.

Sadik, C. D., and Luster, A. D. (2012). Lipid-cytokine-chemokine cascades orchestrate leukocyte recruitment in inflammation. J. Leukoc Biol. 91, 207215. doi: 10.1189/jlb.0811402

Sala, A., Voelkel, N., Maclouf, J., and Murphy, R. C. (1990). Leukotriene E4 elimination and metabolism in normal human subjects. J. Biol. Chem. 265, 21771-21778.

Sala, A., Murphy, R. C., and Voelkel, N. F. (1991). Direct airway injury results in elevated levels of sulfidopeptide leukotrienes, detectable in airway secretions. Prostaglandins 42, 1-7. doi: 10.1016/0090-6980(91)90088-w

Samuelsson, B., Dahlén, S. E., Lindgren, J. A., Rouzer, C. A., and Serhan, C. N. (1987). Leukotrienes and lipoxins: structures, biosynthesis, and biological effects. Science 237, 1171-1176. doi: 10.1126/science.2820055

Sardu, C., Gambardella, J., Morelli, M. B., Wang, X., Marfella, R., and Santulli, G. (2020). Hypertension, thrombosis, kidney failure, and diabetes: is COVID-19 an endothelial disease? A comprehensive evaluation of clinical and basic evidence. J. Clin. Med. 9, E1417. doi: 10.3390/jcm9051417

Sasaki, F., and Yokomizo, T. (2019). The leukotriene receptors as therapeutic targets of inflammatory diseases. Int. Immunol. 31, 607-615. doi: 10.1093/ intimm/dxz044

Secor, W. E., Powell, M. R., Morgan, J., Wynn, T. A., and Funk, C. D. (1998). Mice deficient for 5-lipoxygenase, but not leukocyte-type 12-lipoxygenase, display altered immune responses during infection with Schistosoma mansoni. Prostaglandins Lipid Mediat. 56, 291-304. doi: 10.1016/s0090-6980(98)00059-8

Sprague, R. S., Stephenson, A. H., Dahms, T. E., and Lonigro, A. J. (1989). Proposed role for leukotrienes in the pathophysiology of multiple systems organ failure. Crit. Care Clin. 5, 315-329. doi: 10.1016/S0749-0704(18)30439-1

Tager, A. M., Bromley, S. K., Medoff, B. D., Islam, S. A., Bercury, S. D., Friedrich, E. B., et al. (2003). Leukotriene B4 receptor BLT1 mediates early effector T cell recruitment. Nat. Immunol. 4, 982-990. doi: 10.1038/ni970

Tahan, F., Jazrawi, E., Moodley, T., Rovati, G. E., and Adcock, I. M. (2008). Montelukast inhibits tumour necrosis factor-alpha-mediated interleukin-8 expression through inhibition of nuclear factor-kappaB p65-associated histone acetyltransferase activity. Clin. Exp. Allergy 38, 805-811. doi: 10.1111/j.1365-2222.2008.02963.x

Taube, C., Miyahara, N., Ott, V., Swanson, B., Takeda, K., Loader, J., et al. (2006). The leukotriene B4 receptor (BLT1) is required for effector CD8+ T cellmediated, mast cell-dependent airway hyperresponsiveness. J. Immunol. 176, 3157-3164. doi: 10.4049/jimmunol.176.5.3157

Teuwen, L. A., Geldhof, V., Pasut, A., and Carmeliet, P. (2020). COVID-19: the vasculature unleashed. Nat. Rev. Immunol. May 21, 1-3. doi: 10.1038/s41577020-0343-0

Varga, Z., Flammer, A. J., Steiger, P., Haberecker, M., Andermatt, R., Zinkernagel, A. S., et al. (2020). Endothelial cell infection and endotheliitis in COVID-19. Lancet. 395, 1417-1418. doi: 10.1016/S0140-6736(20)30937-5

Vetter, P., Vu, D. L., L'Huillier, A. G., Schibler, M., Kaiser, L., and Jacquerioz, F. (2020). Clinical features of covid-19. BMJ 369, m1470. doi: 10.1136/bmj.m1470

Viner, R. M., and Whittaker, E. (2020). Kawasaki-like disease: emerging complication during the COVID-19 pandemic. Lancet 395, 1741-1743. doi: 10.1016/S0140-6736(20)31129-6

Wang, Y., Zhang, D., Du, G., Du, R., Zhao, J., Jin, Y., et al. (2020). Remdesivir in adults with severe COVID-19: a randomised, double-blind, placebo-controlled, multicentre trial. Lancet. 395, 1569-1578. doi: 10.1016/S0140-6736(20)31022-9

Wermuth, H. R., Badri, T., and Takov, V. (2020). "Montelukast," in StatPearls [Internet] (Treasure Island, FL: StatPearls Publishing). 2020 Jan-.

Werz, O., and Steinhilber, D. (2006). Therapeutic options for 5-lipoxygenase inhibitors. Pharmacol. Ther. 112, 701-718. doi: 10.1016/j.pharmthera.2006.05.009

Westcott, J. Y., Thomas, R. B., and Voelkel, N. F. (1991). Elevated Urinary Leukotriene E4 Excretion in Patients With ARDS and Severe Burns. Prostaglandins Leukot. Essent. Fatty Acids 43, 151-158. doi: 10.1016/09523278(91)90162-X

Wu, C., Liu, Y., Yang, Y., Zhang, P., Zhong, W., Wang, Y., et al. (2020). Analysis of therapeutic targets for SARS-CoV-2 and discovery of potential drugs by computational methods. Acta Pharm. Sin. B. 10, 766-788. doi: 10.1016/ j.apsb.2020.02.008

Wu, F., Zhao, S., Yu, B., Chen, Y. M., Wang, W., Song, Z. G., et al. (2020). A new coronavirus associated with human respiratory disease in China. Nature 579, 265-269. doi: 10.1038/s41586-020-2008-3

Yao, X. L., Cowan, M. J., Gladwin, M. T., Lawrence, M. M., Angus, C. W., and Shelhamer, J. H. (1999). Dexamethasone alters arachidonate release from human epithelial cells by induction of p11 protein synthesis and inhibition of phospholipase A2 activity. J. Biol. Chem. 274, 17202-17208. doi: 10.1074/ jbc.274.24.17202

Zhang, X., Tan, Y., Ling, Y., Lu, G., Liu, F., Yi, Z., et al. (2020). Viral and host factors related to the clinical outcome of COVID-19. Nature 583, 437-440. doi: 10.1038/s41586-020-2355-0

Zhou, P., Yang, X. L., Wang, X. G., Hu, B., Zhang, L., Zhang, W., et al. (2020). A pneumonia outbreak associated with a new coronavirus of probable bat origin. Nature. 579, 270-273. doi: 10.1038/s41586-020-2012-7

Zhou, Q., Chen, V., Shannon, C. P., Wei, X. S., Xiang, X., and Wang, X. (2020). Interferon- $\alpha 2 b$ Treatment for COVID-19. Front. Immunol. 11, 1061. doi: 10.3389/fimmu.2020.01061

Zhu, N., Zhang, D., Wang, W., Li, X., Yang, B., Song, J., et al. (2020). A Novel coronavirus from patients with pneumonia in China. N. Engl. J. Med. 382, 727733. doi: 10.1056/NEJMoa2001017

Conflict of Interest: AA is the founder and managing director of Novateur Ventures, Inc. CF is a scientific advisor for Novateur Ventures Inc. The authors have applied for a provisional patent for this particular drug combination to treat COVID-19. The authors currently have no commercial or financial relationships with the makers of the two drugs discussed in this article.

Copyright (C) 2020 Funk and Ardakani. This is an open-access article distributed under the terms of the Creative Commons Attribution License (CC BY). The use, distribution or reproduction in other forums is permitted, provided the original author(s) and the copyright owner(s) are credited and that the original publication in this journal is cited, in accordance with accepted academic practice. No use, distribution or reproduction is permitted which does not comply with these terms. 